\title{
Imaging sites of airway obstruction and measuring functional responses to bronchodilator treatment in asthma $^{1}$
}

\author{
SAWTANTRA K CHOPRA, GEORGE V TAPLIN, DONALD P TASHKIN, \\ EVERETT TREVOR, AND DENNIS ELAM
}

From the Division of Pulmonary Disease, Department of Medicine, and Laboratory of Nuclear Medicine and Radiation Biology, Department of Radiological Sciences, University of California School of Medicine, Los Angeles, California, USA

ABSTRACT The sites of airway obstruction and dilatation after terbutaline administration were studied by inhalation imaging and pulmonary function tests in 12 stable asthmatic patients. Inhaled terbutaline as a therapeutic aerosol decreased airway resistance (Raw) and improved radioaerosol (Ae) images in nine, $\Delta \dot{\mathrm{V}} \max _{50}$ in three, and xenon (Xe) images in five of 12 subjects, suggesting that its predominant site of action was on major airways. Subcutaneously injected terbutaline improved Raw, $\Delta \dot{\mathrm{V}} \max _{50}$, and Ae images in 11 and Xe images in eight subjects indicating that it released bronchospasm in the major and minor airways. These findings in asthma suggest that aerosol and Xe imaging procedures are sensitive indicators of large and small airway obstruction respectively.

Inhalation lung imaging and pulmonary function tests were performed repeatedly in a young man for nearly a year after an acute inhalation exposure to ammonia (Taplin et al, 1976). Aerosol images in this man showed excessive deposition in major airways and poor peripheral penetration. After inhalation of isoprenaline, the aerosol images reverted to near normal patterns whereas xenon (Xe) images remained unchanged. Similar findings were also obtained subsequently in a few other individuals with chronic obstructive pulmonary disease. These striking aerosol image changes suggested their possible value in determining the sites of obstruction in bronchial asthma and for showing the sites of action of inhaled and subcutaneously injected bronchodilator drugs.

\section{Methods}

Twelve stable (in remission) asthmatic patients aged 18 to 63 years with mild to severe airway obstruction, none of whom smoked cigarettes, were studied. The severity of asthma was graded on the basis of $\mathrm{FEV}_{1}$ values in percent of pre-

\footnotetext{
${ }^{1}$ Supported by Contract E (04-10) Gen-12 between US Energy Research and Development Agency and the University of California, Los Angeles.
}

dicted; $\quad 70-80 \%=$ mild; $55-70=$ moderate, and $<55=$ severe. Patients were not allowed sodium cromoglycate for at least 24 hours, an oral bronchodilator for at least 12 hours, or an inhaled bronchodilator for at least four hours before study. Subjects with acute respiratory infections during the previous month were excluded.

Baseline lung function tests (PFTs) and lung imaging procedures after inhaling ${ }^{133} \mathrm{Xe}$ and aerosol (Ae) of ${ }^{99^{\mathrm{m}}} \mathrm{Technetium} \mathrm{pertechnetate} \mathrm{were}$ performed in the morning of each of the three study days. After these procedures the patients were treated in random double-blind fashion with either (1) $1 \mathrm{ml}$ of aerosolised terbutaline $(0.5 \mathrm{mg})$ $+0.5 \mathrm{ml}$ saline subcutaneously (SC), (2) $1 \mathrm{ml}$ aerosolised saline $+0.5 \mathrm{ml}$ terbutaline $(0.25 \mathrm{mg}) \mathrm{SC}$, or (3) $1 \mathrm{ml}$ aerosolised saline $+0.5 \mathrm{ml}$ saline SC (placebo). Ten to 30 minutes after each treatment regimen, PFTs and lung imaging procedures were repeated for comparison with baseline findings. The protocol was approved by the UCLA Human Subject Protection Committee, and informed consent was obtained from each patient.

The subjects were evaluated with body plethysmography followed by maximal expiratory flow-volume (FV) curves performed with the subject breathing air and a low density gas $(80 \%$ 
helium-20\% oxygen mixture). Body plethysmographic measurements of airway resistance (Raw) and thoracic gas volume (Vtg) were performed using a 900 litre capacity box according to the method of Dubois et al (1956). Specific airways conductance (sGaw $=1 / \mathrm{Raw} / \mathrm{Vtg}$ ) was calculated to correct for changes in Raw due to changes in $V$ tg. The average of five measurements was used. FV curves were performed using a rolling-seal spirometer (Cardiopulmonary Instrument Model 1220 with an $\mathrm{x}$-y recorder, Hewlett-Packard Model 7041A). At least three FV curves were performed with the subject breathing air followed by three additional FV curves, each obtained after three inspiratory vital capacity breaths of $80 \%$ helium$20 \%$ oxygen, according to the technique described by Hutcheon et al (1974). $\Delta \mathrm{V} \max _{50}$ was calculated as the difference in flow rates at $50 \%$ of the vital capacity between the helium and air FV curves; the method of matching the helium and air FV curves before and after bronchodilator treatment was similar to that described by Antic and Macklem (1976).

Two inhalation lung imaging procedures were performed routinely. Xe lung images were obtained in the posterior projection after inhaling a single breath of 10 millicuries of ${ }^{133} \mathrm{Xe}$ in one litre of oxygen, after rebreathing for eight to ten breaths, and then at 30 -second intervals during $\mathrm{Xe}$ washout for at least three minutes while the patient breathed room air and exhaled into either a vented hood or a shielded 40 litre collection bag.

Radioaerosol lung imaging was performed with the patient in the upright position also in the posterior projection, and images were obtained immediately after inhalation and retention of about two millicuries of ${ }^{99^{\mathrm{m}}} \mathrm{Tech}$ etium pertechnetate $(150 \mathrm{~K}$ counts $/ \mathrm{min} / \mathrm{mCi})$. In place of an ultrasonic aerosol generator used in previous studies (Ramanna et al, 1975; Taplin et al, 1977b), a plastic disposable positive pressure nebuliser* was used. This device when operated at a flow rate of about $10 \mathrm{l} / \mathrm{min}$ with either compressed air or oxygen, converts high specific activity pertechnetate solutions $(10-15 \mathrm{mCi} / \mathrm{ml})$ to a fine aerosol at the rate of $\sim 1.0 \mathrm{ml} / \mathrm{min}$. A six litre plastic reservoir settling bag was placed in the inhalation line between the nebuliser and the patient's mouthpiece to remove large droplets $(>2.0 \mu \mathrm{m})$ from the aerosol (Hayes et al, 1979). The patient breathed the aerosol tidally for two to three minutes or until about two millicuries were deposited in the lungs. In practice, the reservoir bag is first filled with aerosol before the patient is

*Hi-Flow Nebuliser Model 310, W T Farley, Inc, Medical Specialties, 23974 Craftsman Rd, Calabasas, California, 91302. instructed to breathe. When the bag is nearly empty, additional aerosol is delivered until the three-minute administration period is completed. The exhaled gas and radioaerosol are channelled either to a vented hood or to a lead-shielded 40 litre collection bag. The components of the administration system are shown diagrammatically in fig 1, which also lists the sources and manufacturers of the nebuliser and other essential parts of the system.

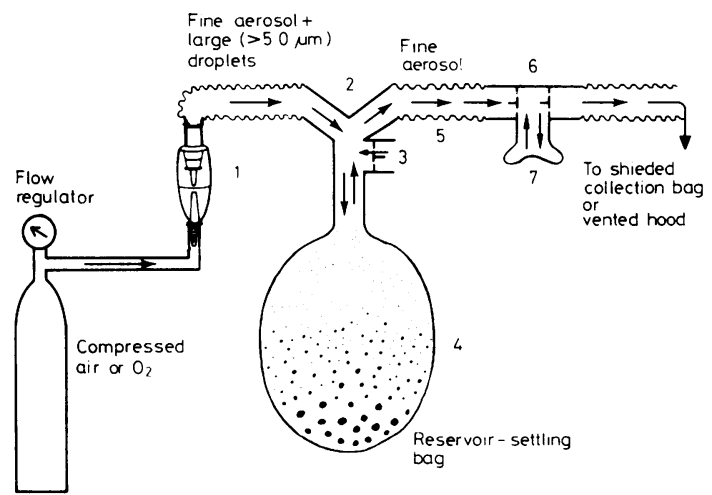

Fig 1 Radioaerosol administration system with large droplet settling bags: (1) Hi-Flow Nebuliser; (2) " $y$ " connector (Inspiron Division, C R Bard Inc, $161 \mathrm{~N}$ Mountain Ave, Upland, California 91738); (3) One-way demand valve (Instrumentation Industries, 215 Thomas Drive, Pittsburgh, Pennsylvania 15236); (4) Settling bag, available as 3; (5) Corrugated tubing; (6) Two-way valve; and (7) Mouthpiece.

The effectiveness of the new system is shown in fig 2 which shows that excessive central deposition of a polydispersed aqueous aerosol occurs when inhaled directly from the "Hi-Flow" nebuliser, whereas a uniform distribution pattern is obtained when the reservoir bag is used. The observation $\frac{D}{2}$ suggests that the aerosol droplets larger than $2 \mu \mathrm{m}$. are removed in the reservoir bag by impaction, $\mathcal{N}$ turbulence, and sedimentation. Furthermore, when $N$ airborne albumin microaggregates smaller than $2 \mu \mathrm{m}$ in greatest dimension (as measured micro- $\frac{\omega}{\sigma}$ scopically after collection on a haemocytometer) are inhaled directly from the nebuliser they are distributed uniformly throughout the lung and no excessive central deposition occurs. These findings provide objective evidence that this nebuliserreservoir system delivers aerosol droplets smaller $\overrightarrow{\mathbb{D}}$ than $2 \mu \mathrm{m}$ diameter.

The rapid absorption of pertechnetate aerosol $\stackrel{\mathbb{D}}{\square}$ permits aerosol lung imaging before and after treatment on the same day (Taplin et al, 1977a). 8 In normal subjects, the half time of removal from? 


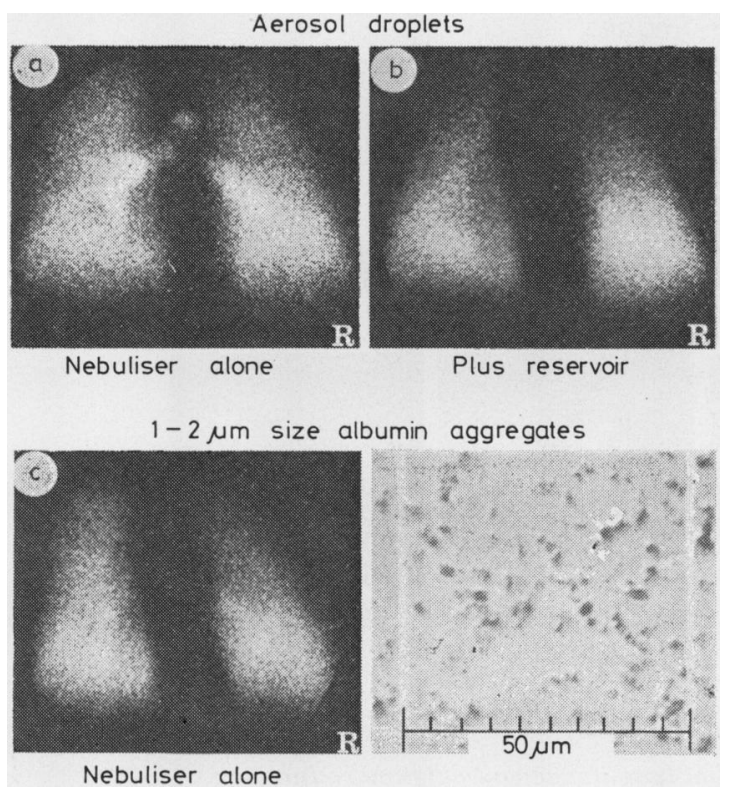

Fig 2 Three aerosol inhalation lung images from same normal subject performed under identical conditions with one exception. (a) Excessive aerosol deposition in central airways (Hi-Flow Nebuliser alone). (b) Normal aerosol distribution (Hi-Flow Nebuliser plus reservoir-settling bag). (c) Normal aerosol distributions with pre-sized particle inhalation.

the peripheral lung is $6-12$ minutes and more than 30 minutes from the major airways.

The criteria for grading improvement in lung images are indicated in table 1 . When initial Ae and $\mathrm{Xe}$ single breath or rebreathing, or both, and washout image remained nearly unchanged from baseline findings, they were graded as zero improvement. Slight to moderate $(+$ to ++ ) improvement in Ae images was shown by decreasing amounts of central deposition along with increas- ing amounts of peripheral penetration. Slight $(+)$ to moderate $(++)$ improvement in $\mathrm{Xe}$ images was noted as a mild $(+)$ to moderate $(++)$ increase in clearance during the washout phase. When definitely abnormal baseline $\mathrm{Ae}$ and $\mathrm{Xe}$ images reverted to normal or near normal patterns, they were graded +++ . The degree of improvement in airway function was graded according to the degree of change in plethysmographic specific airway conductance and in $\Delta V \max _{50}$, respectively (table 1).

\section{Results}

EXAMPLES OF LUNG IMAGES AND PULMONARY FUNCTION RESPONSES TO BRONCHODILATOR TREATMENT

The composite presented in fig 3 illustrates the relation between changes in $\mathrm{Ae}$ images and improvement in function tests after treatment with aerosolised or subcutaneously injected terbutaline or a placebo. On the left, a baseline Ae image characteristic of moderate to severe airway obstruction is shown. There is excessive aerosol deposition in the regions of the major bronchi and only minimal aerosol is deposited throughout peripheral lung. After placebo treatment, the Ae image remained unchanged and sGaw showed less than $25 \%$ improvement. In the next set of images the abnormal baseline picture at the top shows moderately excessive deposition in the major bronchi and slight impairment of aerosol penetration to the lung periphery. After treatment, the image improved and showed only slight central deposition ( + or mild improvement in the $\mathrm{Ae}$ image). Similarly, FEV $_{1}$ and sGaw also improved to a mild degree. The third set of images on the right of the pair just described were considered to indicate ++ improvement. The moderately abnormal baseline image that exhibited excessive deposition in the trachea and the major airways

Table 1 Criteria for grading improvement in airway function and lung images

\begin{tabular}{|c|c|c|c|c|c|}
\hline & Procedures & 0 & + & ++ & +++ \\
\hline \multirow[t]{2}{*}{ Pulmonary function tests } & Specific conductance & $<25$ & $25-50$ & $51-75$ & $>75$ \\
\hline & $\begin{array}{l}\triangle \dot{V}_{\text {Max }} \text { Mo } \\
(\% \text { increase })\end{array}$ & $<25$ & $25-50$ & $51-75$ & $>75$ \\
\hline Aerosol images & Initial & None & $\begin{array}{l}\downarrow \mathbf{C D} \\
\uparrow \mathbf{P P}\end{array}$ & $\begin{array}{l}\downarrow \\
\uparrow \\
\uparrow\end{array}$ & $\begin{array}{l}\text { Near normal } \\
\text { to normal }\end{array}$ \\
\hline Xenon images & $\begin{array}{l}\text { Breathholding } \\
\text { Washout }\end{array}$ & $\begin{array}{l}\text { None } \\
\text { None }\end{array}$ & $\begin{array}{l}\text { None } \\
\uparrow \text { Clearance }\end{array}$ & $\begin{array}{l}\text { Near normal } \\
\uparrow \uparrow \text { Clearance }\end{array}$ & $\begin{array}{l}\text { Normal } \\
\text { Normal }\end{array}$ \\
\hline
\end{tabular}

$\Delta \dot{\mathbf{V}} \mathrm{Max}_{\mathrm{s0}}=$ Change in maximal expiratory flow at $50 \%$ of the vital capacity, comparing flow measured during air breathing and flow measured during $80 \%$ helium $-20 \%$ oxygen breathing.

$\mathrm{CD}=$ Central deposition.

$\mathrm{PP}=$ Peripheral penetration. 


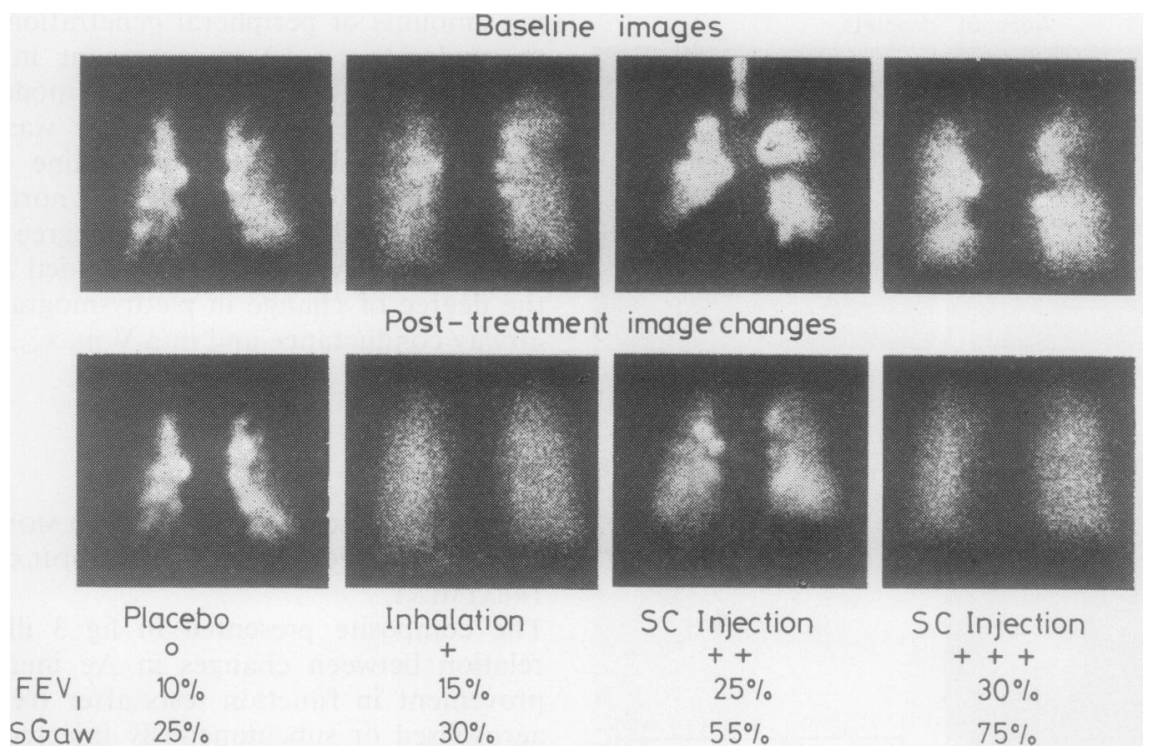

Fig 3 Baseline and post-treatment radioaerosol lung image and pulmonary function changes. For description, see text.

with little or no peripheral penetration, reverted to only a slightly abnormal pattern after subcutaneous terbutaline. Specifically, tracheal deposition disappeared, only a slightly excessive amount of aerosol remained in the central airways, and the peripheral lung had an almost normal distribution pattern. Coinciding with this moderate $(++)$ improvement in the image, sGaw also showed moderate improvement over baseline findings. In the last set of aerosol images on the extreme right, the definitely abnormal image showing excessive central deposition and regionally impaired penetration of aerosol to the lung periphery changed after treatment to an entirely normal pattern with uniform aerosol distribution throughout the lung. This change was considered a +++ response and was consistent with the function tests that showed greater than $75 \% \mathrm{im}$ provement in sGaw over baseline values.

The $\mathrm{Ae}$ and $\mathrm{Xe}$ images (fig 4) represent the responses of three asthmatic patients with moderate to severe airway obstruction. The baseline $\mathrm{Ae}$ and $\mathrm{Xe}$ images in the top row show bilateral abnormalities. The Ae image shows excessive central deposition and regional reduction in peripheral penetration. The Xe rebreath image is likewise abnormal and shows diminished activity in both mid-lung regions. The washout image at 2.0 to 2.5 minutes shows slightly excessive retention in both mid-lung regions with greater retention on the right. After subcutaneous terbutaline, the aerosol and $\mathrm{Xe}$ rebreath and washout images in the middle row all reverted to entirely normal patterns. In contrast, after terbutaline inhalation, only the aerosol image changed to a near-normal pattern, whereas the Xe images remained abnormal. Thus Xe lung images were probably more sensitive indicators of small airway obstruction and dilatation whereas radioaerosol showed the sites and degrees of obstruction in the major airways not visible by $\mathrm{Xe}$ imaging.

\section{INDIVIDUAL RESPONSE TO BRONCHODILATOR TREATMENT}

The degree of improvement in airway function tests and in aerosol and Xe images after each treatment regimen (graded according to the criteria presented in table 1) is indicated in table 2 for each of the 12 asthmatic subjects studied.

\section{SUMMARY OF RESPONSES TO BRONCHODILATOR TREATMENT}

Table 3 summarises the response in lung function and table 4 summarises the response in lung images to treatment with a placebo and terbutaline given by inhalation as an aerosol or by subcutaneous injection. Placebo treatment was followed by little improvement in either function test results or lung image patterns. After inhaled terbutaline, sGaw and Ae images both improved in nine patients. Only slight improvement in $\Delta \vec{V}$ $\max _{50}$ and in Xe imaging occurred, however, and 

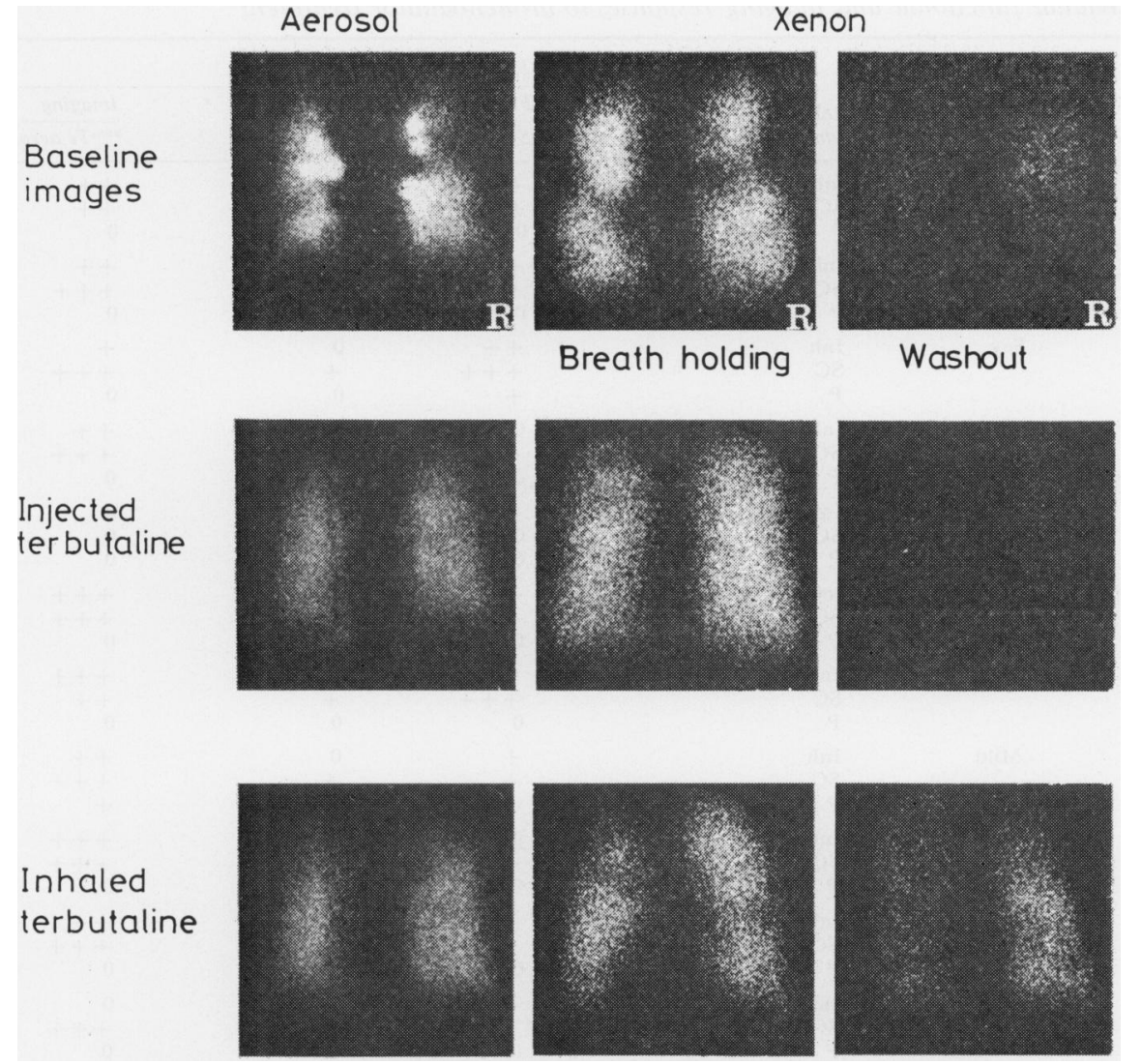

Fig 4 Radioaerosol and xenon lung image findings (responses to injected versus inhaled terbutaline). Note improvement in both aerosol and xenon images after systemic injection of terbutaline whereas only aerosol images improved after inhalation of terbutaline.

was noted in only three and five patients respectively. In comparison, the injected terbutaline was effective in improving both sGaw and $\Delta V \max _{50}$ in 11 of the 12 patients and in converting abnormal $\mathrm{Ae}$ and $\mathrm{Xe}$ images toward normal patterns in 11 and eight patients respectively. No relation was apparent between the severity of asthma as defined by the baseline $\mathrm{FEV}_{1}$ and the sites of airway dilatation after inhaled or injected terbutaline as ascertained from either the PFTs or imaging studies.

\section{Discussion}

RADIOAEROSOL LUNG IMAGES-THEIR INTERPRETATION AND FUNCTIONAL SIGNIFICANCE Before bronchodilator treatment, all 12 asthmatic subjects had lung images with similar abnormal distribution patterns-namely, excessive aerosol deposition in the major or central airways associated with varying degrees of impaired penetration to the lung periphery. Similar abnormalities have been observed by Despas et al (1970). These abnormal image patterns reverted towards normal almost immediately after terbutaline treatment. The image changes coincided with improvement in sGaw (a measure of large airway function) and remained unaltered after the placebo regimen.

Large airway obstruction in asthma is caused by reversible bronchospasm, excess mucus in the airways, and thickening of the bronchial wall by oedema and inflammation. These abnormalities promote excessive deposition of inhaled aerosol droplets in the large airways by gravitational sedimentation and turbulent impaction (Newhouse et $a l, 1976)$. As a result, there is considerable reduction in the proportion of the total inhaled dose reaching and remaining in the terminal airways 
Table 2 Individual functional and imaging responses to bronchodilator treatment

\begin{tabular}{|c|c|c|c|c|c|c|c|}
\hline \multirow{3}{*}{$\begin{array}{l}\text { Patient } \\
\text { no }\end{array}$} & \multirow{3}{*}{$\begin{array}{l}\text { Age } \\
(y r)\end{array}$} & \multirow{3}{*}{$\begin{array}{l}\text { Severity of } \\
\text { asthma* }\end{array}$} & \multirow{3}{*}{$\begin{array}{l}\text { Route of } \\
\text { administration } \dagger\end{array}$} & \multicolumn{4}{|c|}{ Responses to treatment $\ddagger$} \\
\hline & & & & \multicolumn{2}{|c|}{ Functional } & \multicolumn{2}{|l|}{ Imaging } \\
\hline & & & & SGaw & $\Delta \dot{\mathbf{V}} \operatorname{Max}_{\text {so }}$ & ${ }^{99 m}$ Tc aerosol 1 & ${ }^{133} \mathrm{Xe}$ \\
\hline 1 & 63 & Mod & $\begin{array}{l}\text { Inh } \\
\text { SC } \\
\text { P }\end{array}$ & $\begin{array}{l}++ \\
++ \\
0\end{array}$ & $\begin{array}{l}0 \\
++ \\
0\end{array}$ & $\begin{array}{l}++ \\
++ \\
0\end{array}$ & $\begin{array}{l}0 \\
0 \\
0\end{array}$ \\
\hline 2 & 25 & Mod & $\begin{array}{l}\text { lnh } \\
\text { SC } \\
\text { P }\end{array}$ & $\begin{array}{l}+ \\
0\end{array}$ & $\begin{array}{l}+ \\
+ \\
0\end{array}$ & $\begin{array}{l}++ \\
++ \\
0\end{array}$ & $\begin{array}{l}0 \\
++ \\
0\end{array}$ \\
\hline 3 & 35 & Sev & $\begin{array}{l}\text { Inh } \\
\text { SC } \\
\text { P }\end{array}$ & $\begin{array}{l}++ \\
++ \\
+\end{array}$ & $\begin{array}{l}0 \\
+ \\
0\end{array}$ & $\begin{array}{l}+ \\
0\end{array}$ & $\begin{array}{l}0 \\
0\end{array}++$ \\
\hline 4 & 18 & Mod & $\begin{array}{l}\text { Inh } \\
\text { SC } \\
\text { P }\end{array}$ & $\begin{array}{l}0 \\
+ \\
0\end{array}$ & $\begin{array}{l}0 \\
+ \\
0\end{array}$ & $\begin{array}{l}++ \\
++ \\
0\end{array}$ & $\begin{array}{l}0 \\
0 \\
++\end{array}$ \\
\hline 5 & 56 & Sev & $\begin{array}{l}\text { Inh } \\
\text { SC } \\
\text { P }\end{array}$ & $\begin{array}{l}++ \\
0 \\
0\end{array}$ & $\begin{array}{l}+ \\
0 \\
0\end{array}$ & $\begin{array}{l}0 \\
0 \\
0\end{array}$ & $\begin{array}{l}0 \\
0 \\
0\end{array}$ \\
\hline 6 & 44 & Mild & $\begin{array}{l}\text { Inh } \\
\text { SC } \\
\text { P }\end{array}$ & $\begin{array}{l}+ \\
0\end{array}$ & $\begin{array}{l}0 \\
+ \\
0\end{array}$ & $\begin{array}{l}+++ \\
+++ \\
0\end{array}$ & $\begin{array}{l}+ \\
0 \\
0\end{array}$ \\
\hline 7 & 54 & Sev & $\begin{array}{l}\text { Inh } \\
\text { SC } \\
\text { P }\end{array}$ & $\begin{array}{l}++ \\
+++ \\
0\end{array}$ & $\begin{array}{l}0 \\
+ \\
0\end{array}$ & $\begin{array}{l}+++ \\
++ \\
0\end{array}$ & $\begin{array}{l}0 \\
+ \\
0\end{array}$ \\
\hline 8 & 47 & Mild & $\begin{array}{l}\text { Inh } \\
\text { SC } \\
\text { P }\end{array}$ & $\begin{array}{l}+ \\
+ \\
0\end{array}$ & $\begin{array}{l}0 \\
+ \\
0\end{array}$ & $\begin{array}{l}++ \\
++ \\
+\end{array}$ & $\begin{array}{l}+ \\
+ \\
+\end{array}$ \\
\hline 9 & 24 & Mild & $\begin{array}{l}\text { Inh } \\
\text { SC } \\
\text { P }\end{array}$ & $\begin{array}{l}0 \\
+ \\
0\end{array}$ & $\stackrel{+}{++}$ & $\begin{array}{l}+++ \\
+++ \\
0\end{array}$ & $\begin{array}{l}+ \\
++ \\
0\end{array}$ \\
\hline 10 & 18 & Sev & $\begin{array}{l}\text { Inh } \\
\text { SC } \\
\mathbf{P}\end{array}$ & $\begin{array}{l}+++ \\
+++ \\
0\end{array}$ & $\begin{array}{l}+ \\
+ \\
0\end{array}$ & $\begin{array}{l}++ \\
++ \\
0\end{array}$ & $\begin{array}{l}+ \\
+\end{array}$ \\
\hline 11 & 25 & Sev & $\begin{array}{l}\text { Inh } \\
\text { SC } \\
\text { P }\end{array}$ & $\begin{array}{l}++ \\
++ \\
0\end{array}$ & $\begin{array}{l}0 \\
0 \\
0\end{array}$ & $\begin{array}{l}0 \\
+ \\
0\end{array}$ & $\begin{array}{l}0 \\
0 \\
0\end{array}$ \\
\hline 12 & 18 & Mild & $\begin{array}{l}\text { Inh } \\
\text { SC } \\
\text { P }\end{array}$ & $\begin{array}{l}0 \\
+ \\
0\end{array}$ & $\begin{array}{l}0 \\
+ \\
0\end{array}$ & $\begin{array}{l}0 \\
++\end{array}$ & $\begin{array}{l}0 \\
++ \\
0\end{array}$ \\
\hline
\end{tabular}

*Severity of asthma: see text.

$\dagger$ Route of medication: $\mathrm{Inh}=$ Inhaled terbutaline $(0.5 \mathrm{mg}) ; \mathrm{SC}=$ Subcutaneous terbutaline $(0.25 \mathrm{mg}) ; \mathrm{P}=$ placebo.

$\ddagger$ Response to treatment : see table 1 for criteria for grading improvement in airway function and in aerosol and $\mathrm{Xe}$ images.

Table 3 Summary of responses of airway function to bronchodilator treatment $(n=12)$

\begin{tabular}{|c|c|c|c|c|c|}
\hline \multirow{2}{*}{$\begin{array}{l}\text { Route of drug } \\
\text { administration }\end{array}$} & \multirow[t]{2}{*}{ Test } & \multicolumn{4}{|c|}{ Improvement in airway function } \\
\hline & & $\begin{array}{l}\text { No of } \\
\text { subjects } \\
\text { improved }\end{array}$ & $\begin{array}{c}\text { Deg } \\
\text { imp } \\
+\end{array}$ & $\begin{array}{c}\text { ree of } \\
\text { roveme } \\
++\end{array}$ & +++ \\
\hline Inhalation & $\begin{array}{l}\text { SGaw } \\
\Delta \dot{\mathbf{V}} \mathbf{M a x}_{30}\end{array}$ & $\begin{array}{l}9 \\
3\end{array}$ & $\begin{array}{l}3 \\
3\end{array}$ & $\begin{array}{l}5 \\
0\end{array}$ & $\begin{array}{l}1 \\
0\end{array}$ \\
\hline Injection & $\begin{array}{l}\text { SGaw } \\
\Delta \dot{V} \mathbf{M a x}_{50}\end{array}$ & $\begin{array}{l}11 \\
11\end{array}$ & $\begin{array}{l}3 \\
8\end{array}$ & $\begin{array}{l}3 \\
2\end{array}$ & $\begin{array}{l}5 \\
1\end{array}$ \\
\hline Placebo & $\begin{array}{l}\text { SGaw } \\
\Delta \dot{\mathbf{V}} \mathbf{M a x} \text { so }_{0}\end{array}$ & $\begin{array}{l}1 \\
0\end{array}$ & $\begin{array}{l}1 \\
0\end{array}$ & $\begin{array}{l}\mathbf{0} \\
\mathbf{0}\end{array}$ & $\begin{array}{l}\mathbf{0} \\
\mathbf{0}\end{array}$ \\
\hline
\end{tabular}

and alveoli, in contrast to the retention of as much as 80 to $90 \%$ of insoluble aerosol of the same size $(<2 \mu \mathrm{m})$ in normal subjects (Lippman and Albert, 1969; Albert et al, 1973). The abnormal deposition
Table 4 Summary of responses of lung images to bronchodilator treatment $(n=12)$

\begin{tabular}{llllll}
\hline $\begin{array}{l}\text { Route of drug } \\
\text { administration }\end{array}$ & \multicolumn{1}{l}{ Improvement in lung images } \\
\cline { 2 - 6 } & $\begin{array}{l}\text { Type of } \\
\text { image }\end{array}$ & $\begin{array}{l}\text { Nubjects } \\
\text { improved }\end{array}$ & $\begin{array}{l}\text { Degree of } \\
\text { improvement } \\
+\end{array}$ & $++\quad+++$ \\
\hline Inhalation & Aerosol & 9 & 1 & 4 & 4 \\
& Xe & 5 & 5 & 0 & 0 \\
Injection (SC) & Aerosol & 11 & 0 & 3 & 8 \\
& Xe & 8 & 1 & 6 & 1 \\
Placebo & Aerosol & 1 & 1 & 0 & 0 \\
& Xe & 2 & 1 & 1 & 0 \\
\hline
\end{tabular}

of the bulk of an inhaled small-particle aerosol in the central airways of asthmatic patients is indicative of large airway obstruction. These findings on Ae imaging are different from those ob- 
tained with ${ }^{133} \mathrm{Xe}$ which follows the airstream from the mouth to the alveoli without detectable deposition in the airways. When partial obstruction of small airways is present, however, regions distal to the obstruction become visible during the washout phase of the Xe examination as areas in which the gas is retained for longer periods than in the surrounding normally ventilated lung (Taplin et $a l, 1977 \mathrm{~b})$. The abnormal Xe images were often reversible after bronchodilator treatment, and these changes showed fair agreement with improvement in $\Delta V \max _{50}$, a measurement that probably reflects small airways resistance.

\section{SITE OF ACTION OF TERBUTALINE}

Controversy exists regarding the primary sites of airway obstruction in bronchial asthma (Despas et al, 1972; Mildon et al, 1974; Antic and Macklem, 1976; Chan-Yeung et al, 1976). The relative effects of bronchodilator treatment on central and peripheral airway obstruction in asthma have not previously been studied in detail by aerosol and $\mathrm{Xe}$ imaging methods. The finding that $\mathrm{Xe}$ single-breath and washout images were relatively normal in some of the patients in the present study despite functional evidence and Ae image changes suggestive of central airway obstruction is consistent with the previous observations of others (Despas et al, 1972; Antic and Macklem, 1976) that the major site of obstruction is often located in central rather than peripheral airways. Inhaled terbutaline gave definite improvement in sGaw and $\mathrm{Ae}$ images only, whereas improvement in sGaw, $\Delta V \max _{50}$, aerosol, and Xe images followed injected terbutaline (tables 3 and 4). These differences are probably related to the higher concentration of the aerosolised drug in the partially obstructed central bronchi than in the smaller peripheral airways. In patients with moderate to severe asthma inhaled aerosols of about $2 \mu \mathrm{m}$ deposit excessively in the central airways and relatively little is detectable in the peripheral lung. By contrast, in normal subjects, the same size aerosol reaches the terminal airways and alveoli where the bulk of the inhaled dose is deposited depending on its solubility. Therefore, assuming that the inhaled terbutaline as a therapeutic aerosol had about the same size and distribution in the major airways as the pertechnetate aerosol, it is reasonable to assume that its major effect was a topical one on the central airways. These findings also suggest that after an initial inhalation of terbutaline to relieve obstruction of the large airways, repeated inhalations might then permit more drug to reach the peripheral airways and relieve obstruction at these sites as well. This hypothesis warrants further study. The injected drug by its systemic action relieves obstruction affecting both the central and peripheral airways.

We appreciate the help of $\mathrm{Mr}$ Enoch Lee, $\mathrm{Mr}$ Jack Wanger, Mrs Mary Lee Griswold, Mr Hector Pimental, Norman S MacDonald, PhD, Mrs Linda Olt, and Astra Pharmaceuticals Inc.

\section{References}

Antic, R, and Macklem, P T (1976). The influence of clinical factors on site of airway obstruction in asthma. American Review of Respiratory Disease, 114, 851-859.

Albert, R E, Lippmann, M, Peterson, H T, Berger, J, Sanborn, K, and Bohning, D (1973). Bronchial deposition and clearance of aerosols. Archives of Internal Medicine, 131, 115-127.

Chan-Yeung, M, Abboud, R, Tsao, M S, and Maclean, L (1976). Effect of helium on maximal expiratory flow in patients with asthma before and during induced bronchoconstriction. American $R e$ view of Respiratory Disease, 113, 433-443.

Despas, P F, Leroux, M, and Macklem, P T (1972). Site of airway obstruction in asthma as determined by measuring maximal expiratory flow breathing air and a helium-oxygen mixture. Journal of Clinical Investigations, 51, 3235-3243.

Despas, P, Walker, A, MacRae, J, and Read, J (1970). Inhalation and perfusion lung scans in bronchial asthma. Australasian Annals of Medicine, 4, 304 309.

Dubois, A B, Botelho, S Y, Bedell, G N, Marshall, $R$, and Comroe, J S (1956a). A rapid plethysmographic method for measuring thoracic gas volume: A comparison with a nitrogen washout method for measuring functional residual capacity in normal subjects. Journal of Clinical Investigation, 35, 322326.

Dubois, A B, Botelho, S Y, and Comroe, J H (1956b). A new method for measuring airway resistance in man using a body plethysmograph; values in normal subjects and patients with respiratory disease. Journal of Clinical Investigation, 35, 327-335.

Hayes, M, Taplin, G V, Chopra, S K, Knox, D, and Elam, D (1979). Improved radioaerosol administration system for routine inhalation lung imaging. Radiology, 131, 256-258.

Hutcheon, M, Griffin, P, Levison, $H$, and Zamel, N (1974). Volume of isoflow: A new test in detection of mild abnormalities of lung mechanics. American Review of Respiratory Disease, 110, 458-465.

Lippmann, M, and Albert, R E (1969). The effect of particle size on the regional deposition of inhaled aerosols in the human respiratory tract. American Industrial Hygiene Association Journal, 30, 257275.

Mildon, A, Leroux, M, Hutcheon, M, and Zamel, N (1974). The site of airways obstruction in exercise- 
induced asthma. American Review of Respiratory Disease, 110, 409-414.

Newhouse, M, Sanchis, J, and Bienenstock, J (1976). Lung defense mechanisms. (First of two parts). New England Journal of Medicine, 295, 990-998.

Ramanna, L, Tashkin, D P, Taplin, G V, Elam, D, Detels, R, Coulson, A, and Rokaw, S N (1975). Radioaerosol lung imaging in chronic obstructive pulmonary disease (comparison with pulmonary function tests and roentgenography). Chest, 68, 634-640.

Taplin, G V, Chopra, S K, Yanda, R L, and Elam, D (1976). Radionuclidic lung-imaging procedures in the assessment of injury due to ammonia inhalation. Chest, 69, 582-586.
Taplin, G V, Chopra, S K, and Elam, D (1977a). Imaging experimental pulmonary ischemic lesions after inhalation of a diffusible radioaerosol. Journal of Nuclear Medicine, 18, 250-254.

Taplin, G V, Tashkin, D P, Chopra, S K, Anselmi, O E, Elam, D, Calvarese, B, Coulson, A, Detels, R, and Rokaw, S N (1977b). Early detection of chronic obstructive pulmonary disease using radionuclide lung imaging procedures. Chest, 71, 567575 .

Requests for reprints to: Sawtantra K Chopra, MD, Division of Pulmonary Disease, Department of Medicine, UCLA Center for the Health Sciences, Los Angeles, California 90024.

\section{The Society for Clinical Trials}

The above society has recently been organised to promote the development and exchange of information on clinical trials methodology and on research using similar methods. The Society plans to achieve these goals through meetings and publications and by attracting members from various disciplines. Membership is open to anyone interested. For further information, and to apply for membership, please write to Dr C R Klimt, Secretary, Society for Clinical Trials, Inc, 600 Wyndhurst Ave, Baltimore MD 21210, USA. 